\title{
Design and Development of Microcontroller based Solar Powered College Bell
}

\author{
Ramesh Harajibhai Chaudhari ${ }^{1}$, Bhagyalaxmi R. Rajgor ${ }^{1}$, V.M. Modi ${ }^{1}$, Vinay Patel $^{1}$, \\ Dhaval Chaudhari ${ }^{1}$ and Alok Gora ${ }^{2 *}$ \\ ${ }^{1}$ College of Renewable Energy \& Environmental Engineering, ${ }^{2}$ C.P. College of Agriculture \\ SDAU, Sardarkrushinagar, India \\ *Corresponding author
}

\section{A B S T R A C T}

\section{Keywords}

Automation, Microcontroller, Rely, Real Time Clock, Electrical Coil, Solar PV System, Clapper, Keypad

Article Info

Accepted:

12 March 2019

Available Online:

10 April 2019
The world over the decades has made considerable advancement in automation; it is employed in homes, industries, commercial and educational sectors. In present work, a solar power-operated microcontroller-based automatic college bell is designed and developed. For the harmonic tuning, converted normal college bell into automatic college bell and powered by solar PV system with battery backup. It uses electrical coil for generating the EMF for striking the clapper on the edge of a bell for making sound. It uses the Real Time Clock (DS1307) which tracks the real time. The microcontroller (ATMEGA $328 \mathrm{p}$ ) is used to control all the functions; it gets the time through the keypad and stores it in its memory. When programmed time equals the real time then the bell is switched on via a relay for a predetermined time. The bell ringing time can be edited at any time so that it can be reused again and again at normal class timings as well as at exam times. The advantage of this design is that the bell rings at the start of each period without any human intervention to a great degree of accuracy and hence takes over the manual task of switching on/off the college bell with respect to time. It works on onetime time setup.

\section{Introduction}

A bell is a percussion instrument used in schools or colleges that tells the students when it is time to go to class in the morning and when it is time to change classes during the day. No other instrument can do such work. So the bell is an important instrument in schools, industries and other businesses offices where the bell timer plays a critical role in running the day (Wikipedia, 2011).
Because of in today's life, everyone gives importance to time and time does not wait for anybody. Everything should be performed in time and with accuracy. Now a day's school or college bells are operated manually and they are using electrical bell. Hence there is a big question of accuracy and tuning of an electric bell is not like by most of the people. Also, there is a necessity of manpower and money. Hence here we should use automatic control system, which saves our manpower 
and money and also it gives the highest accuracy (Bulgogi Santhosh Kumar).

In this research model, the scope is to design a mechanism for converting manual college bell into the automatic college bell and its implementation on Arduino Uno board. An automatic college bell is powered by solar PV system and $12 \mathrm{~V}$ battery connected for power backup in cloudy condition or absence of sunlight. An Automatic College Bell is a digital circuit that is used for the purpose of automatic switching of the bell as per the given schedule without any human intervention. The shape of the bell is hollow cup so that when struck vibrates in a single strong strike by internally connected clapper and creates a harmonic tune. This type of bells is usually made from a bronze metal or other hard material. It is generally based on the casting method and bell metals are used around $80 \%$ copper and $20 \%$ tin by mass it means approximately a copper to tin ratio is $4: 1$. The higher tin content increases the rigidity and also resonance of the metal, and because of higher tin content, it has been found empirically to give the most pleasant tone and also the tone of a bell is mostly due to its shape.

\section{Materials and Methods}

The present study was adopted at the College of Renewable Energy and Environmental Engineering, Sardarkrushinagar Dantiwada Agricultural University, Sardarkrushinagar. All the research work was carried out at the College Campus and study area falls under $23^{0} 52^{\prime} \mathrm{N}$ latitude, $72^{0} 43^{\prime} \mathrm{E}$ longitude and at an altitude of $209 \mathrm{~m}$ above mean sea level.

\section{Existing system/working}

In the existing market, there are many electrical bells are available with digital clocks but they ringing on only at a specific time. Many researchers have been worked on automatic microcontroller based bell but they have used an electrical bell, also they used the grid power source. All these limits have been removed by the current research project and ringing will play according to the college time table.

Developed system demonstrates a simple configuration of a circuit of automatic college bell using Microcontroller. It is designed fully automatic and once data is entered the college bell rings after a regular interval as per the programmers need and the timing may be varied in between to include breaks.

It also displays real time and temperature. The developed model of microcontroller based solar powered college bell system is shown in figure 1 and 2 .

\section{Power supply unit}

Solar PV panel (10 watt) is used as a main power source. $12 \mathrm{~V}$ and 7Ah Lead-acid battery is used for continues power supply and power storage. A 100 watt power rating capacity converter is used for convert the 12 Volt DC power in to AC power $50 \mathrm{~Hz}$ frequency for bell system. A power required for the microcontroller circuit operation and pull-up resistors is $230 \mathrm{~V}$.

A $230 \mathrm{~V}$ power supply required for coil operation through relay. The power supply required for LCD display operation is $5 \mathrm{~V}$ DC from solar charge regulator or $5 \mathrm{~V}$ adaptor. RTC is powered with 3V DC CR1220 cell.

\section{Main components of the bell system}

\section{Solar panel}

A multi crystalline type panel was used for main power source of the bell system; its power rating capacity is 10 watt DC. 


\section{Charge controller}

Charge controller is device which prevents battery from overcharging and over discharging and also block reverse current flow from battery to panel during night; its power rating capacity is $12 \mathrm{~V}$ and $6 \mathrm{Amp}$.

\section{Rechargeable battery}

A battery is a device consisting of one or more electrochemical cells that convert stored chemical energy into electrical energy. Leadacid battery of $12 \mathrm{~V}$ and $7 \mathrm{AH}$ is used.

\section{Power converter}

A power converter is an electronic device or circuitry that changes direct current (DC) to alternating current $(\mathrm{AC})$. The input voltage is $12 \mathrm{~V} \mathrm{DC}$ and it gives output voltage $230 \mathrm{~V}$ and frequency $50 \mathrm{~Hz}$. A $100 \mathrm{~W}$ power rating capacity of converter is used in between battery and load (college bell).

\section{Arduino uno microcontroller board}

The Arduino microcontroller board is the important part of the bell system. It is configured with AVR micro controller by ATMEGA Company. Controller will take care of the main logic of the project. The controller ATMEGA 328p is the 32 bit processor means it will transfer 32 bit of data simultaneously. The UNO is one of the more popular boards in the Arduino family and a great choice for engineering programming demonstration.

\section{RTC (Real Time Clock)}

A real-time clock (RTC) is a battery-powered clock that is used for track the real time. DS1307 RTC is used it will also sense the room temperature and show on LCD display of micro controller.

\section{LCD display}

The 2 line $\mathrm{x} 16$ character LCD modules are used cause of it is widely available from a manufacturers. It is used to display the real time, temperature and alarm timings. The time is displayed in the $\mathrm{HH}: \mathrm{MM}$ format and room temperature in degree centigrade.

\section{Keypad}

A 4x4 keypad unit of digits, symbols and a complete set of alphabetical letters are used. It is used to initialize the RTC, modify the alarm timings, alarm numbers, ringing time and save or erase alarms. Various keys of keypad are following: (1) 0 to 9 (2) A, B, C, D (3) * and \#

Pressing ' $\mathrm{A}$ ' will change the main menu and Pressing ' $\mathrm{B}$ ' will also change the menu but in reverse order.

Pressing ' $\mathrm{D}$ ' will delete all saved data.

Pressing * will save all alarm.

\section{Relay}

A relay is an electromagnetic switch operated by a relatively small electric current/voltage that can turn on or off a much larger current/voltage. In our case when real time clock is matched with the alarm that we have entered the micro controller will trigger relay which will act as a close switch for college bell and the main power circuit of college bell will complete and alarm will start to ring.

\section{Memory (EEPROM)}

EEPROM stands for Electrically Erasable Programmable Read-Only Memory and is a type of memory used in computers, integrated in microcontrollers for smartcards and remote keyless systems, and other electronic devices to store relatively small amounts of data but allowing individual bytes to be erased and 
reprogrammed. It can be read, erased, and rewritten electronically. It is used for stores data even with the power removed. EEPROM is Flash memory type which is designed for high speed and high density, at the expense of large erase blocks (512 bytes or larger) and limited number of write cycles $(10,000)$.

\section{Coil}

An electromagnetic coil is a device comprising of a conductor and a core. The conductor is most commonly made from solid copper wire, which is wrapped around a solid metal core. Each time the wire is looped around the core, it is called a turn. Multiple turns are considered to be a coil. It is used for EMF generate.

\section{Performance of solar power system}

The performance of all components is explained below.

\section{Performance of solar panel}

The performance of solar panel was tested for various power characteristics and also compared with rated data. The average solar radiation was $910 \mathrm{~W} / \mathrm{m}^{2}$ and temperature was $32{ }^{\circ} \mathrm{C}$ maximum power output from panel was 8.33 watt. The rated maximum voltage was 19.25 V and current was 0.47 Amp whereas; from test it was $17.73 \mathrm{~V}$ and 0.47 Amp. Solar panel was fixed on $23^{\circ}$ tilt angel in south direction.

\section{Performance of rechargeable battery}

Performance of battery was evaluated during bell ringing with charging and without charging condition.

The performance of battery during charging, the variations of voltage of battery and solar radiation with different alarms are shown in figure 3 .
From the figure 3, it can be seen; in the morning session voltage of battery is continuously increase but in evening session it is going down with decreasing of radiation also so the power consumption is low then voltage feeding by solar panel is seen through this graph.

Performance of Battery in without charging condition was analyzed for estimation of battery backup time for bell. The variations of battery voltage with number of alarms ringing are shown in figure 4.

From the figure 4 , it can be seen the voltage of battery continuously decreasing for every alarm $0.07-0.10$ voltage consumed by bell. According to this result backup time of battery for this design is 3 days.

\section{Results and Discussion}

So, coming to the results, The program have been written in such a fashion that, the bell should ring simultaneously as per alarm setup along with the display of the time and temperature on the LCD screen indicating the completion of a particular session and beginning of another session exactly at that instant of time at which the bell rings continuously for 1 to 59 seconds (as per setup) from the movement it is activated. Here, in our implementation, the bell rings at 9:15 instants of time in a day's schedule which is according to the program we have assigned.

\section{Working of bell system}

This design takes the task of ringing the bell in college as the bell is ring automatically at the scheduled time. Microcontroller based systems have made lot of things automatically and easy to use. This is very wonderful design to control the working of college bell. 
230 volt $\mathrm{AC}$ input is given to the Arduino and relay circuit for operation, 5 volt DC supply is given to the LCD display circuit and microcontroller circuit by the adapter from the $\mathrm{DC}$ to AC converter. The Microcontroller AT89S52 is used to control all the Functions; it gets the different setup of time through the keypad and stores it in its Memory. We used key pad with different functional keys, so can be resetting the alarms as per requirement and also can be save number of alarms for different time as well as can be save ringing time also. So, it can be use at normal class timing as well as exam time. LCD is used for display the current time, temperature as well as different input settings. The Real Time Clock (DS1307) is used to provide real time which is displayed at the LCD screen. The control signals of relay and data signals of display, keypad is connected to the Arduino.

Real time clock tracks over the programmed alarm time when both time gets equalisation then RTC send the instruction to the Arduino. Then Arduino Uno will send the power relieve command to the relay (Fig. 5 and 6). Then relay will supply the $230 \mathrm{~V}$ to the coil as per operator need, for ringing duration at school for long bell or for short bell. Relay gives the power supply to the magnetic coil. When the switch is open, an electric current passes through the winding so, coil will working as an electromagnet. It creates a magnetic field that attracts another part of coil which is connected with iron arm. On the bottom end of iron arm single small size hammer is fitted. This iron arm's called the clapper through which the magnetic field clapper is pulling it over the edge of the bell and forcefully strike on edge. It makes sound. After ringing duration microcontroller will discontinue the power supply of coil and this opens a pair of electrical coil. The magnetic field of the electromagnet collapses and the clapper springs away from the bell. This closes the contacts again, allowing the current flow to the electromagnet again, so the magnet pulls the clapper over to strike the bell again. This cycle repeats rapidly many times per second, resulting in a continuous ringing.

Fig.1 Developed College Bell System

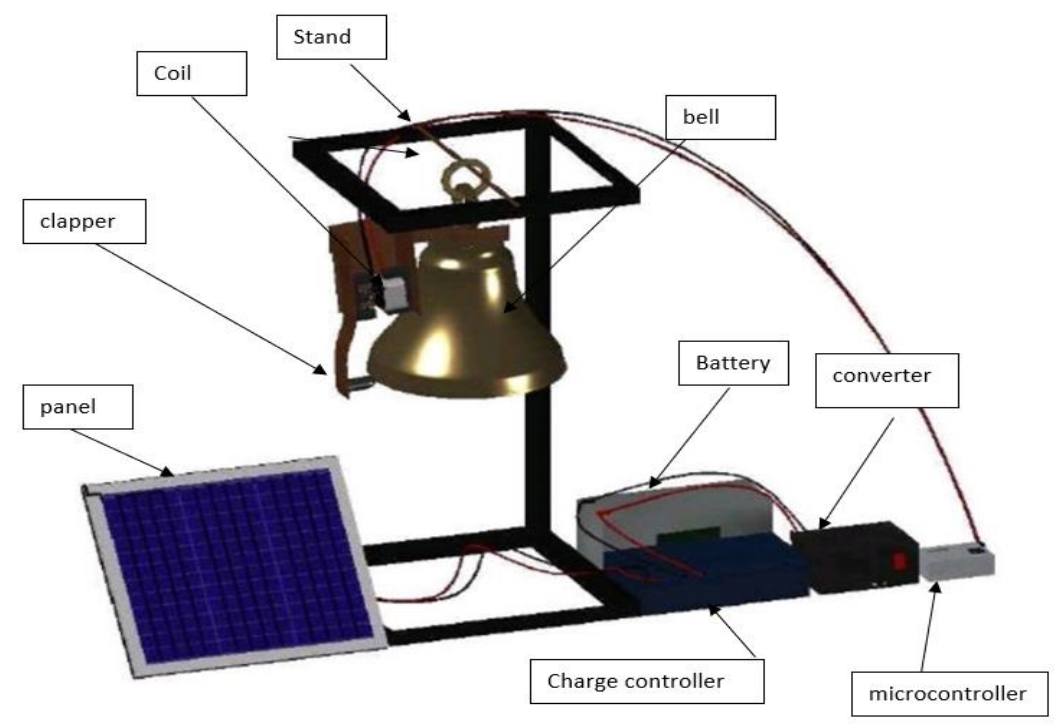


Fig.2 Block diagram of components and process of the bell system

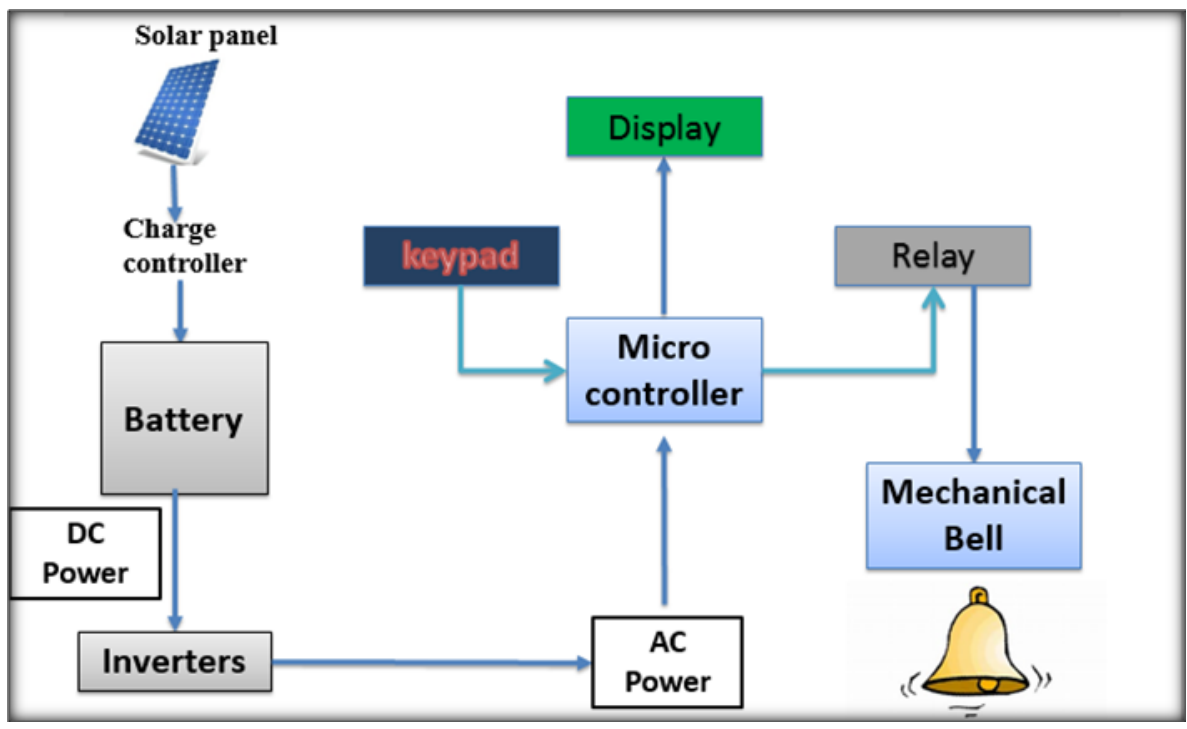

Fig.3 Variation of battery voltage with respect to alarm time during charging

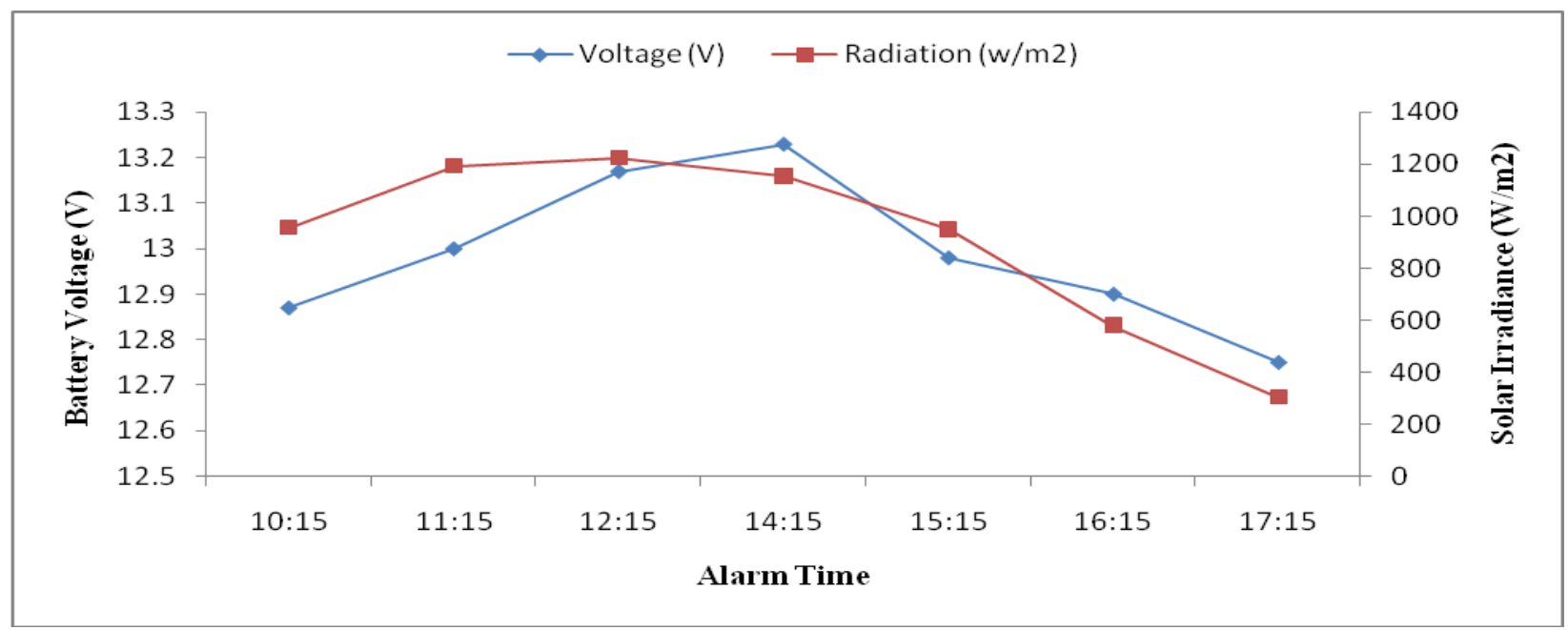

Fig.4 Variation of battery voltage with number of alarms (bell system)

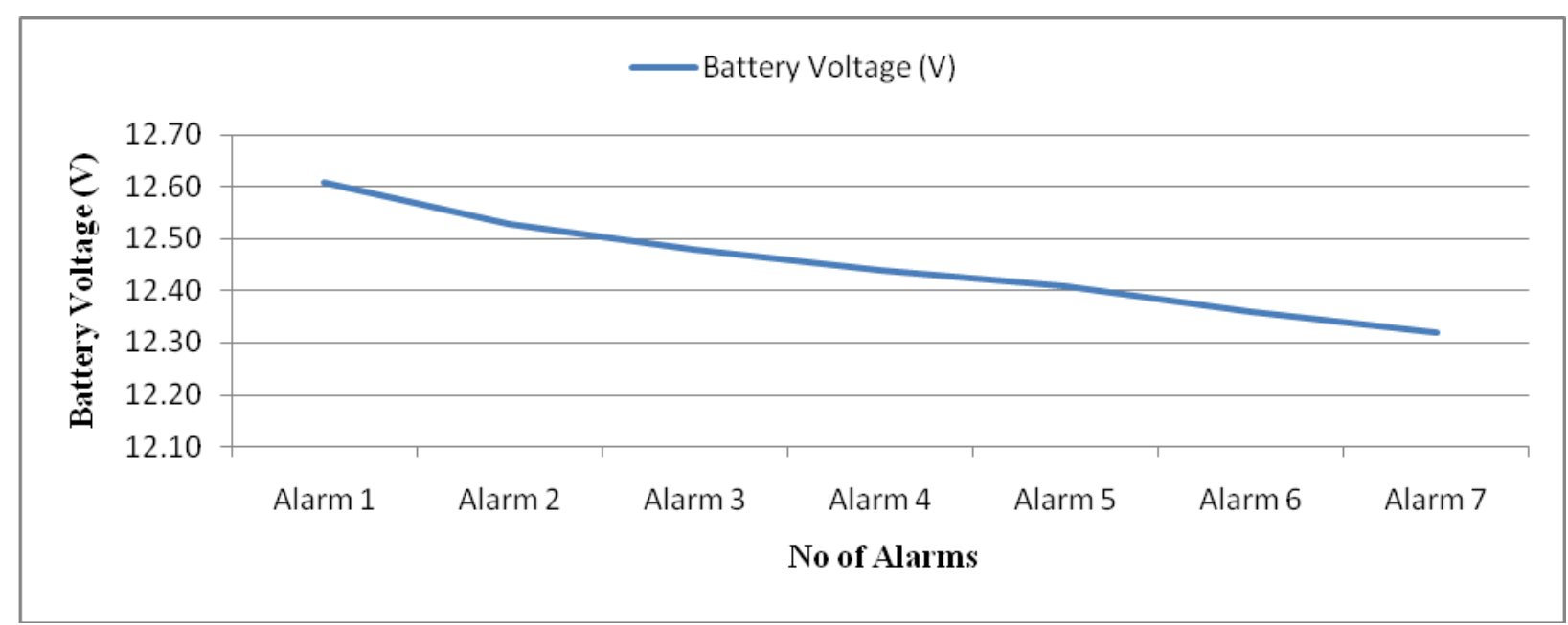


Fig.5\&6 Arduino Uno microcontroller board \& Working of system

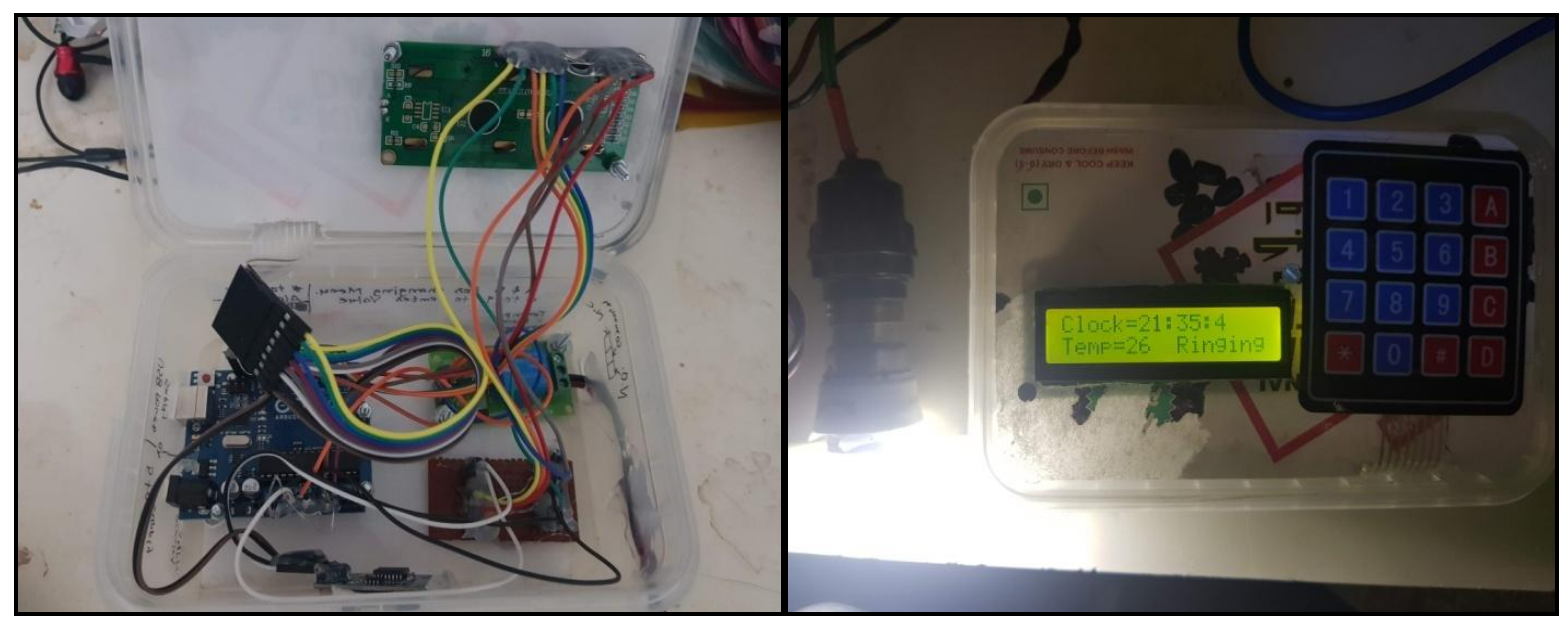

Which attract a springy iron armature with clapper. When an electric current flows through the coils, the electromagnet creates a magnetic field which pulls the armature towards it, causing the clapper to strike the bell. It generates EMF. The rod of the clapper is connected with the coil so when the power supply is on then clapper strike on the edge of the bell. Mechanical bell rings according to the time settings at different time intervals when relay provides the power supply to an electrical coil.

First of all, when electric current flow through the coil, the road become magnet and attracts a piece of iron attached to a clapper. The clapper come close to the bell and hit the bell and makes it sound.

The most widely used from is the interrupter electrical bell, which produces a continuous sound when current is applied. The bell, which is often in the shape of a cup or halfsphere, is struck by a spring-loaded arm with a metal ball on the end called a clapper, actuated by an electromagnet. In its rest position the clapper is held away from the bell a short distance by its springy arm.

In conclusion, in present time world are going for automation accuracy and time saving, in the energy sector they are going for nonconventional energy sources. Here, automatic college bell can be successfully designed on microcontroller based automated operation and also power by solar PV system. It can be applicable in school and colleges as per to save manpower and also to save time and decrease the human error. It will give maximum accuracy and as per the timing which can be easily reprogrammed by a common laymen and can also vary timing for some classes as per the schedule of the college. We can say that it will be much useful for colleges or schools or other educational institutions. It can be built using easily available equipment and can be used in real time in schools and in colleges. The world technology is going to more and more in automation for less man and money saving. It will also help in industries for performing different operation in specific time interval.

\section{References}

Abubakar Isa, H. K. Verma, Abdurrahman Shuaibu, and Mubarak Auwal Saleh. (2018). Implementation of Microcontroller Based Distance Relay. European Journal of Electrical and Computer Engineering. 2 (5):17-21. 
Abyash Gautam, Deepak Rasaily, Sejal Dahal. (2016). Microcontroller Controlled Automated College Bell. International Journal of Engineering Trends and Technology. 32 (4): 184187.

Adedoyin M. A., Olopade o.I., Shoewu O. O., Ogunlewe A.O. (2018). Design and Implementation of Microcontroller Based Calculator. Journal of computation in biosciences and engineering. 1(2):1-4.

Burgoji Santhosh Kumar (2018). Implementation of Automatic College Bell System Using Arduino. International Journal of Current Engineering and Scientific Research. 5 (4): 367-371.

Henry Ohiani Ohize, Elizabeth Nonye Onwuka and Ahmed Ibrahim. (2011). Design of Microcontroller-Based Automatic School Bell. AU J.T. 15(2): 121-128.

https://learn.sparkfun.com/tutorials/what-isan-arduino/

https://www.electronicshub.org/arduinointroduction/

Liping Guo, Paul Curtis, Andrew Barendregt, and Anthony Surillo (2009). Design and Implementation of A Sun Tracking Solar Power System.
American Society for Engineering Education,:14.122.1- 14.122.11.

Shabnum Rasool Shaikh, Snehal Suryakant Kale, Arti Ashokrao Suryawanshi, Prof. Chalkikar G.V. (2018). Arduino based Real Time Clock with Ringing of Bell and National Anthem. International Journal on Recent and Innovation Trends in Computing and Communication. 6 (6): 33-35.

Sheenu Choudhary, Shrikant and Priyanka Sharma. (2014). Automatic college bell system. International Journal of scientific research and management. 2 (3): 668-673.

Syed Naveed Uddin, Mohd Omer Nawaz, T.Kalinga Raj, and Shaik Mahammed Rasool (2017). Automatic School Bell with User defined Time Schedule. International Journal of Advanced Research in Electrical, Electronics and Instrumentation Engineering. 6 (2): 994-998.

Vaishnavi.D.R, Neha Khanum, Apoorva Singh A and Sumaya Afreen (2017). Automated College Bell System with Wireless Control. International Journal of Advanced Research in Electrical, Electronics and Instrumentation Engineering. 6 (5): 3340-3345.

\section{How to cite this article:}

Ramesh Harajibhai Chaudhari, Bhagyalaxmi R. Rajgor, V.M. Modi, Vinay Patel, Dhaval Chaudhari and Alok Gora. 2019. Design and Development of Microcontroller based Solar Powered College Bell. Int.J.Curr.Microbiol.App.Sci. 8(04): 1326-1333. doi: https://doi.org/10.20546/ijcmas.2019.804.154 